\title{
Strontium Bismuth Tantalate Layered Ferroelectric Ceramics: Reaction Kinetics and Thermal Stability
}

\author{
Chung-Hsin Lu* \& Jiun-Ting Lee \\ Department of Chemical Engineering, National Taiwan University, Taipei, Taiwan
}

(Received 22 October 1996; accepted 2 January 1997)

\begin{abstract}
Using $\mathrm{BiTaO}_{4}$ as the precursor, ferroelectric strontium bismuth tantalate $\mathrm{SrBi}_{2} \mathrm{Ta}_{2} \mathrm{O}_{9}$ was successfully synthesized. Heating the mixtures of $\mathrm{BiTaO}_{4}$ and $\mathrm{SrCO}_{3}$ at $800^{\circ} \mathrm{C}$ resulted in the entire formation of a single phase $\mathrm{SrBi}_{2}$ $\mathrm{Ta}_{2} \mathrm{O}_{9}$. The formation process of this compound was verified to be a direct reaction occurring between the reactants without the presence of intermediates. The conversion of $\mathrm{SrBi}_{2} \mathrm{Ta}_{2} \mathrm{O}_{9}$ was isothermally analyzed for exploring the reaction kinetics. The results revealed that the formation process was controlled by the diffusion process. Based on the Ginstling-Brounshtein and Jander models, the activation energy of the diffusion process was estimated to be $194.3 \mathrm{~kJ} \mathrm{~mol}^{-1}$ and $210.7 \mathrm{~kJ} \mathrm{~mol}^{-1}$, respectively. $\mathrm{Sr}_{2} \mathrm{Bi}_{2} \mathrm{Ta}_{2} \mathrm{O}_{9}$ was found to become unstable when heated at above $1200^{\circ} \mathrm{C}$. Once the decomposition process started, this compound was dissociated into $\mathrm{SrTa}_{2} \mathrm{O}_{6}$ and $\mathrm{Bi}_{2} \mathrm{O}_{3}$ from surface to interior. (C) 1998 Elsevier Science Limited and Techna S.r.1. All rights reserved
\end{abstract}

\section{INTRODUCTION}

Ferroclectrics which can retain their polarization state after the removal of applied electric field have been intensively investigated for their application to of the nonvolatile memory. ${ }^{1}$ The ferroelectric lead zirconate titanate (PZT)-based ceramics have been considered for the memory application; however, when metals are used as electrodes, the PZT system exhibits a serious degradation of the maximum and remnant polarization after long-term switching cycles of electric field. ${ }^{2}$ This fatigue behavior becomes extremely detrimental in terms of practical use. On the other hand, the other ferroelectric material-strontium bismuth tantalate $\mathrm{SrBi}_{2} \mathrm{Ta}_{2} \mathrm{O}_{9}$ using platinum as electrodes has been found recently to possess excellent fatigue endurance even after $10^{12}$ cycles of operation. ${ }^{3,4}$ Because of this discovery, an entirely new approach for improving the fatigue problem of ferroelectrics has started.

*To whom correspondence should be addressed.
The crystalline structure of $\mathrm{SrBi}_{2} \mathrm{Ta}_{2} \mathrm{O}_{9}$ belongs to the layered-type perovskite ferroelectrics. ${ }^{5}$ The structure of $\mathrm{SrBi}_{2} \mathrm{Ta}_{2} \mathrm{O}_{9}$ consists of the perovskitelike $\mathrm{TaO}_{6}$ octahedron layers and $\mathrm{Bi}_{2} \mathrm{O}_{2}$ layers. The $\mathrm{TaO}_{6}$ octahedrons construct continuous layers perpendicular to c-axis direction, but in the c-axis direction these octahedrons are separated by the $\mathrm{Bi}_{2} \mathrm{O}_{2}$ layers. The presence of the $\mathrm{Bi}_{2} \mathrm{O}_{2}$ layers has been thought to serve as the shock-absorber for enduring the fatigue of polarization. ${ }^{3}$ The ceramic form of $\mathrm{SrBi}_{2} \mathrm{Ta}_{2} \mathrm{O}_{9}$ was first synthesized by Aurivillius, ${ }^{5}$ and its dielectric properties and phase transformation were later studied by Smolenskii ${ }^{6}$ and Subbarao. ${ }^{7}$ As for thin films, Desu ${ }^{8}$ and Dat ${ }^{9}$ utilized the pulse laser deposition technique for synthesis, $\mathrm{Li}^{10}$ used MOCVD process, and Araujo, ${ }^{3}$ Chu, ${ }^{11}$ and Amanuma ${ }^{12}$ adopted solution-deposition methods for processing. Excellent electrical properties of $\mathrm{SrBi}_{2} \mathrm{Ta}_{2} \mathrm{O}_{9}$ thin films were found in the above researches.

$\mathrm{SrBi}_{2} \mathrm{Ta}_{2} \mathrm{O}_{9}$ has been investigated by several research groups; however, for synthesizing the powder or ceramic form, only the conventional 
process which uses mixed reactants has been undertaken. In our previous study, ${ }^{13}$ a novel process using $\mathrm{BiTaO}_{4}$ as the precursor had successfully prepared another layered-perovskite $\mathrm{BaBi}_{2} \mathrm{Ta}_{2} \mathrm{O}_{9}$. In this new process, the production of intermediates was suppressed, and the formation of $\mathrm{BaBi}_{2} \mathrm{Ta}_{2} \mathrm{O}_{9}$ was markedly accelerated. The obtained powder having a reduced particle size exhibited an enhanced sinterability. For investigating the feasibility of synthesizing $\mathrm{SrBi}_{2} \mathrm{Ta}_{2} \mathrm{O}_{9}$ by using $\mathrm{BiTaO}_{4}$ precursors, in the present study, the mixtures of $\mathrm{BiTaO}_{4}$ and $\mathrm{SrCO}_{3}$ were used as the starting materials for synthesis. In order to better control the reaction processes, the formation mechanism and reaction kinetics in the formation of $\mathrm{SrBi}_{2} \mathrm{Ta}_{2} \mathrm{O}_{9}$ were studied. The most applicable kinetic models were determined for analyzing the rate-controlling process and the activation energy of reaction. Furthermore, the thermal stability and the decomposition reaction of $\mathrm{SrBi}_{2} \mathrm{Ta}_{2} \mathrm{O}_{9}$ at elevated temperatures were also examined.

\section{EXPERIMENTAL}

$\mathrm{BiTaO}_{4}$ and $\mathrm{SrCO}_{3}$ were used as the starting materials for synthesizing $\mathrm{SrBi}_{2} \mathrm{Ta}_{2} \mathrm{O}_{9}$. For preparing the $\mathrm{BiTaO}_{4}$ precursors, equal moles of reagentgrade $\mathrm{Bi}_{2} \mathrm{O}_{3}$ and $\mathrm{Ta}_{2} \mathrm{O}_{5}$ were ball-milled in ethanol in a polyethylene jar for $48 \mathrm{~h}$. Following drying in a rotary evaporator under reduced pressure, the dried powder was heated at $900^{\circ} \mathrm{C}$ for $2 \mathrm{~h}$ to obtain pure $\mathrm{BiTaO}_{4}$. The obtained $\mathrm{BiTaO}_{4}$ powder was subsequently mixed in proportion with $\mathrm{SrCO}_{3}$, followed by the analogous ball-milling and drying processes as described above. Then the dried powder was used in the following experiments.

The mixtures of $\mathrm{BiTaO}_{4}$ and $\mathrm{SrCO}_{3}$ were subjected to differential thermal analysis (DTA) and thermogravimetry analysis (TGA) for tracing the reaction processes. The heating rate was $10^{\circ} \mathrm{C}$ $\min ^{-1}$ and alumina powder was used as reference. For realizing the phase change during reaction, the mixtures were heated in an electric furnace at the same heating rate as that in the thermal analysis, and were quenched in air at various temperatures. The change of the phase formation in the quenched specimens was identified via X-ray powder diffraction (XRD) analysis using $\mathrm{CuK}_{\alpha}$ radiation. The microstructures of the quenched specimens were observed using a scanning electronic microscope (SEM).

In order to explore the reaction kinetics of $\mathrm{SrBi}_{2} \mathrm{Ta}_{2} \mathrm{O}_{9}$, the mixed powder was isothermally heated in TGA. The weight loss of the specimens was automatically recorded by a personal computer.
The weight loss at each reaction condition was calculated and converted into the fractional conversion of reaction. For examining the thermal stability of $\mathrm{SrBi}_{2} \mathrm{Ta}_{2} \mathrm{O}_{9}$, the synthesized pure compound were pressed into pellets, and these pellets were heated at temperatures ranging from $1100^{\circ} \mathrm{C}$ to $1300^{\circ} \mathrm{C}$. The compounds formed on the surface and in the bulk of the heated specimens were identified via XRD.

\section{RESULTS AND DISCUSSION}

\subsection{Formation process of $\mathrm{SrBi}_{2} \mathrm{Ta}_{2} \mathrm{O}_{9}$}

Figure 1 illustrates the TGA and DTA curves of the starting material of $\mathrm{SrBi}_{2} \mathrm{Ta}_{2} \mathrm{O}_{9}$ from room temperature to $1100^{\circ} \mathrm{C}$. On the TGA curve the specimen weight gradually decreased at $600^{\circ} \mathrm{C}$ and above, and the total weight loss increased to be around $4.1 \%$ at $750^{\circ} \mathrm{C}$. No further weight loss was found at higher temperatures. On the DTA curve a broad endotherm was observed at temperature ranging from $600^{\circ} \mathrm{C}$ to $750^{\circ} \mathrm{C}$. This temperature range was the same as that of weight loss. For realizing the reaction mechanism, the starting materials were heated and quenched at various temperatures. The representative XRD patterns for quenched specimens are shown in Fig. 2; in addition, Fig. 3 illustrates the relative content of each phase against the quenching temperature. At $500^{\circ} \mathrm{C}$ only the reactants $\mathrm{SrCO}_{3}$ and $\mathrm{BiTaO}_{4}$ were present, indicating that no reactions occurred. From $600^{\circ} \mathrm{C}$ a small amount of $\mathrm{SrBi}_{2} \mathrm{Ta}_{2} \mathrm{O}_{9}$ started to produce. With the rise in heating temperatures, the amount of $\mathrm{SrBi}_{2} \mathrm{Ta}_{2} \mathrm{O}_{9}$ rapidly increased;

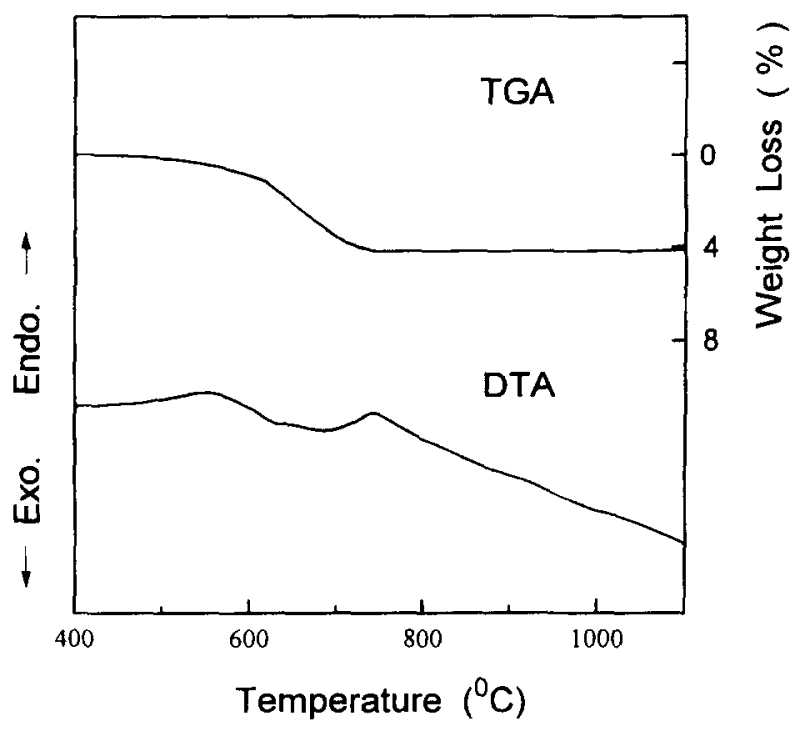

Fig. 1. Differential thermal analysis and thermogravimetry analysis of the starting materials of $\mathrm{SrBi}_{2} \mathrm{Ta}_{2} \mathrm{O}_{9}$. 


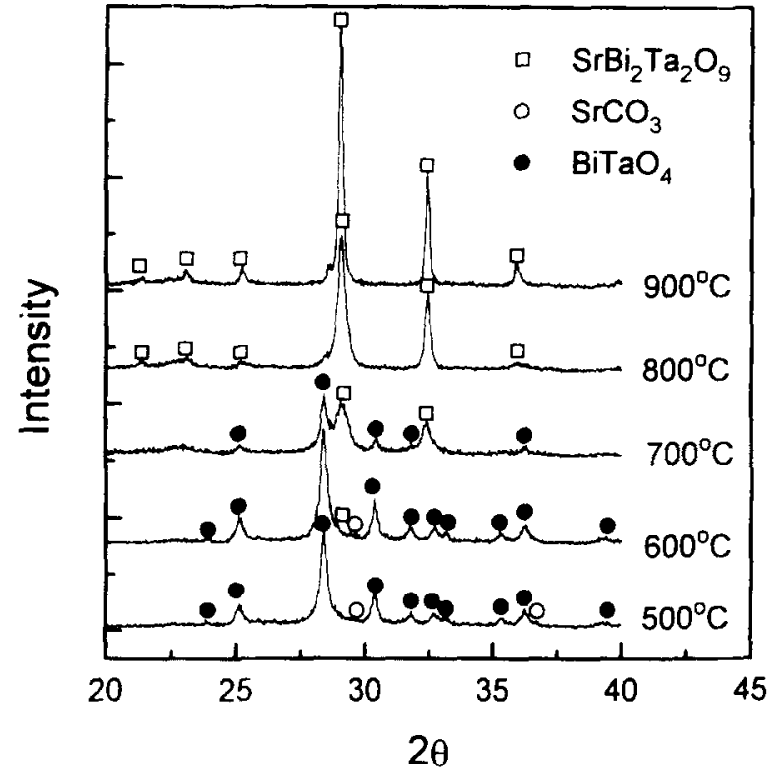

Fig. 2. X-ray diffraction intensity of the starting materials of $\mathrm{Sr}_{\mathrm{Bi}} \mathrm{Ta}_{2} \mathrm{O}_{9}$ heated at various temperatures.

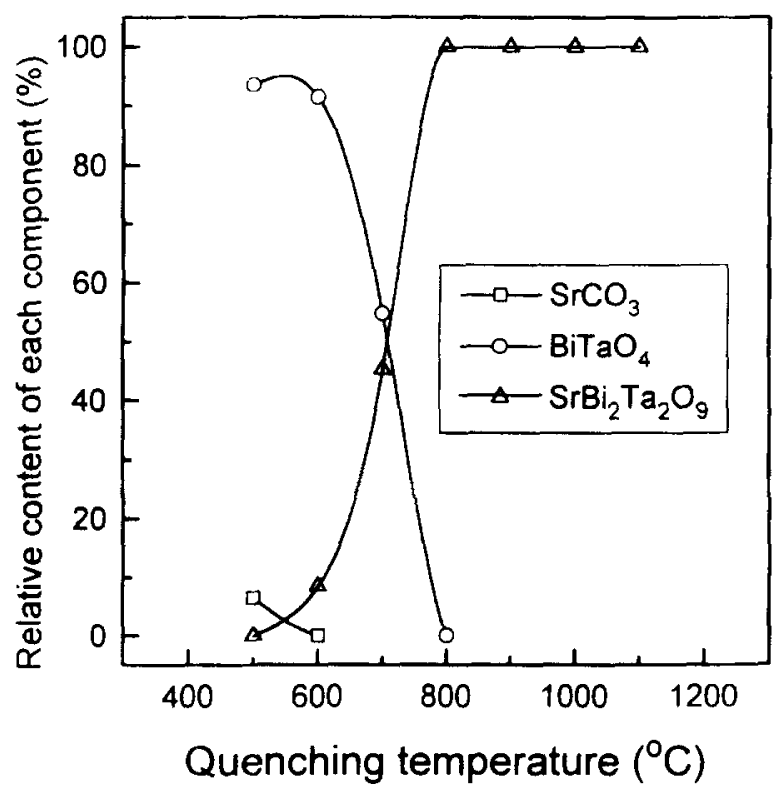

Fig. 3. Relative contents of the resulting compounds during heating the starting materials of $\mathrm{SrBi}_{2} \mathrm{Ta}_{2} \mathrm{O}_{9}$ at various temperatures

whereas those amounts of $\mathrm{BiTaO}_{4}$ and $\mathrm{SrCO}_{3}$ correspondingly decreased. When the temperature reached $800^{\circ} \mathrm{C}$, both reactants were entirely consumed, revealing that the formation of $\mathrm{SrBi}_{2} \mathrm{Ta}_{2} \mathrm{O}_{9}$ was complete. On further heating to $900^{\circ} \mathrm{C}$, the crystallinity of this compound was enhanced. The above XRD results indicated that $\mathrm{SrBi}_{2} \mathrm{Ta}_{2} \mathrm{O}_{9}$ was successfully synthesized via the new reaction routes using $\mathrm{BiTaO}_{4}$ as the precursor. Furthermore, the high reactivity between $\mathrm{BiTaO}_{4}$ and $\mathrm{SrCO}_{3}$ when the heating temperature reached $800^{\circ} \mathrm{C}$ resulted in the complete formation of $\mathrm{SrBi}_{2} \mathrm{Ta}_{2} \mathrm{O}_{9}$. SEM analysis showed that the synthesized $\mathrm{SrBi}_{2} \mathrm{Ta}_{2} \mathrm{O}_{9}$ powder had an uniform morphology. The particle size of the $800^{\circ} \mathrm{C}$-quenched sample was around 0.05 $0.15 \mu \mathrm{m}$, and that of the $900^{\circ} \mathrm{C}$-quenched sample was enlarged to $0.1-0.2 \mu \mathrm{m}$.

According to the results of Figs 2 and 3, the weight loss on TGA in Fig. I was ascribed to the release of carbon dioxide from $\mathrm{SrCO}_{3}$ for producing $\mathrm{SrBi}_{2} \mathrm{Ta}_{2} \mathrm{O}_{9}$, and meanwhile the formation of $\mathrm{SrBi}_{2} \mathrm{Ta}_{2} \mathrm{O}_{9}$ resulted in the endotherm on DTA. Based on the results in Fig. 3, the reaction mechanism of $\mathrm{SrBi}_{2} \mathrm{Ta}_{2} \mathrm{O}_{9}$ was confirmed to be a direct reaction occurring between two reactants without the presence of any intermediate compounds. Therefore, the formation of $\mathrm{SrBi}_{2} \mathrm{Ta}_{2} \mathrm{O}_{9}$ can be elucidated by the following equation:

$$
\mathrm{SrCO}_{3}+2 \mathrm{BiTaO}_{4} \rightarrow \mathrm{SrBi}_{2} \mathrm{Ta}_{2} \mathrm{O}_{4}+\mathrm{CO}_{2}
$$

The above equation satisfies the requirement of mass balance.

\subsection{Reaction kinetics of $\mathrm{SrBi}_{2} \mathrm{Ta}_{2} \mathrm{O}_{9}$}

The formation of $\mathrm{SrBi}_{2} \mathrm{Ta}_{2} \mathrm{O}_{9}$ is associated with the vaporization of carbon dioxide from $\mathrm{SrCO}_{3}$ as expressed in eqn (1), therefore the data of weight loss can be used to calculate the conversion in reactions. The starting materials were isothermally heated at 600,630 , and $660^{\circ} \mathrm{C}$ for $60 \mathrm{~min}$. The percentage weight loss at each temperature is plotted against reaction time as shown in Fig. 4. This figure indicates that when the reaction time was fixed, the weight loss increased with higher temperatures. Based on eqn (1), the theoretical weight loss is 4.17 $\%$ when the entire reaction is complete. Therefore the fractional conversion $(\alpha)$ of eqn (1) can be

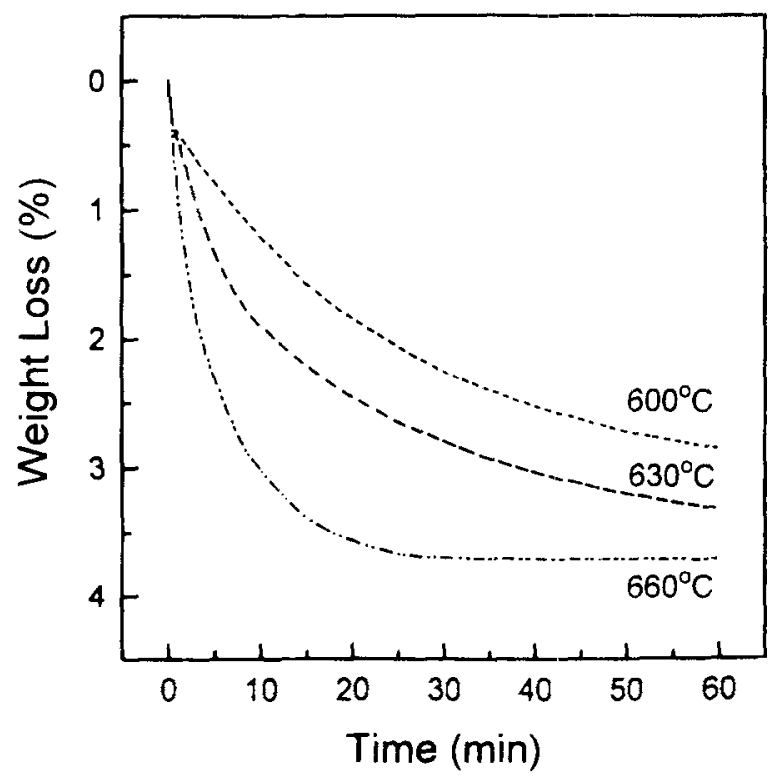

Fig. 4. Weight loss of the starting materials heated at 600 , 630 , and $660^{\circ} \mathrm{C}$, respectively. 


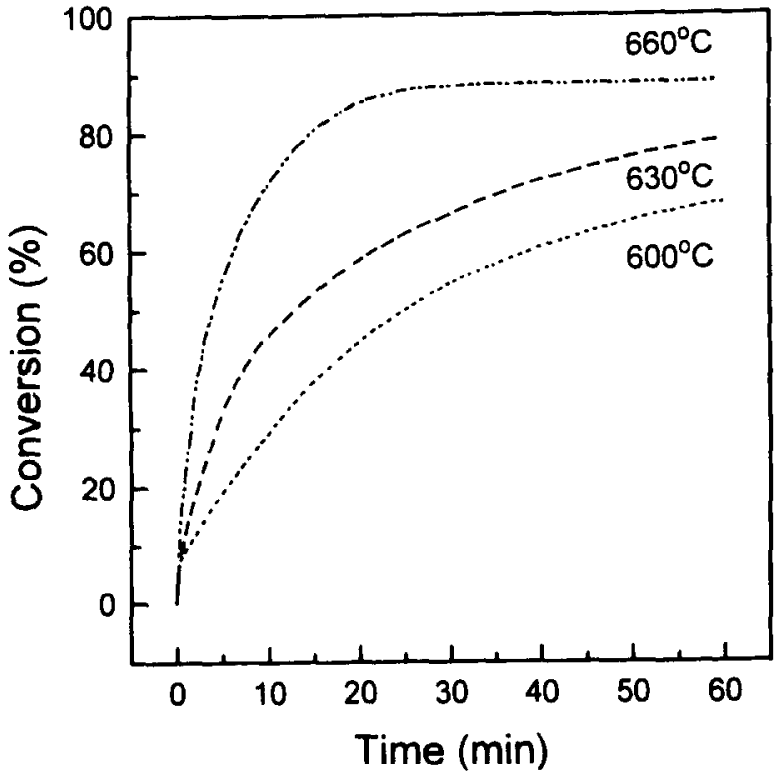

Fig. 5. Conversion ratio of $\mathrm{SrBi}_{2} \mathrm{Ta}_{2} \mathrm{O}_{9}$ vs reaction time at 600,630 , and $660^{\circ} \mathrm{C}$, respectively.

defined as being the ratio of the experimental weight loss to the theoretical weight loss. Figure 5 illustrates the relation between the conversion ratios and reaction conditions. At all three temperatures, the conversion ratio monotonously rose with longer reaction time. It is noted that at the same reaction period, the conversion increased with a rise in the heating temperature. After reacting for $60 \mathrm{~min}$, the conversion ratios at 600 and $630^{\circ} \mathrm{C}$ were 68 and $77 \%$, respectively. On the other hand, the conversion at $660^{\circ} \mathrm{C}$ reached nearly around $89 \%$ after only $25 \mathrm{~min}$ of reaction. Figure 5 indicates that the conversion was enhanced with an increase in reaction tempcrature and time.

In order to analyze the reaction kinetics of $\mathrm{SrBi}_{2} \mathrm{Ta}_{2} \mathrm{O}_{9}$, the Hancock and Sharps' method ${ }^{14}$ based on the Avrami-Erofe'ev equation ${ }^{15,16}$ was adopted. According to this method, a generalized equation is applicable to identify the classification of reaction kinetics. The linear form of this equation is expressed as

$$
\ln (-\ln (1-\alpha))=\ln B+m \ln t
$$

where $\alpha$ is the conversion ratio, $t$ the reaction time, and $\mathrm{B}$ a constant which is determined by nucleation frequency and grain growth rate. The slope $m$ obtained by plotting the left-hand term in eqn (2) against $\ln t$ is a characteristic value depending on the controlling mechanism in solid-state reactions. When $m=0.54-0.62$, the mechanism belongs to the diffusion-controlled type. For $m=1.0-1.24$, a zero-order, first-order, or phase-boundary controlled mechanism is implied. When $m=2.0-3.0$, the reaction mechanism is classified to be the nucleation and growth-controlled type.
Figure 6 shows $\ln (-\ln (1-\alpha))$ plotted against vs In (time), and three straight lines were obtained as a result. The values of $m$ at 600,630 , and $660^{\circ} \mathrm{C}$ were estimated to be $0.61,0.61$, and 0.66 , respectively. According to Hancock and Sharps' study, ${ }^{14}$ the type of diffusion-controlled mechanism is considered to dominate the reaction of $\mathrm{SrBi}_{2} \mathrm{Ta}_{2} \mathrm{O}_{9}$. Among the diffusion-controlled models, ${ }^{14}$ considering that the reactions took place among particles in three-dimension, the GinstlingBrounshtein ${ }^{17}$ and Jander's ${ }^{18}$ models were chosen to fit the relation between conversion and reaction time. The former model is expressed as

$$
1-2 \alpha / 3-(1-\alpha)^{2 / 3}=\mathrm{kt}
$$

and the latter one is expressed as

$$
\left[1-(1-\alpha)^{1 / 3}\right]^{2}=\mathrm{kt}
$$

where $\mathrm{k}$ is the reaction rate constant. The above two functions of $\alpha$ were plotted against reaction time, and the linearity coefficients and the values of $\mathrm{k}$ for eqns (3) and (4) are summarized in Table 1. The data in this table indicate that the lines derived from both Ginstling-Brounshtein and Jander's models exhibited good linearity at all three temperatures. In view of the fact that eqns (3) and (4) hold well throughout the reaction process, the Ginstling-Brounshtein and Janders' models can properly describe the reaction mechanism of $\mathrm{SrBi}_{2} \mathrm{Ta}_{2} \mathrm{O}_{9}$. Using the data of $\mathrm{k}$ listed in Table 1 and Arrhenius's equations cited below:

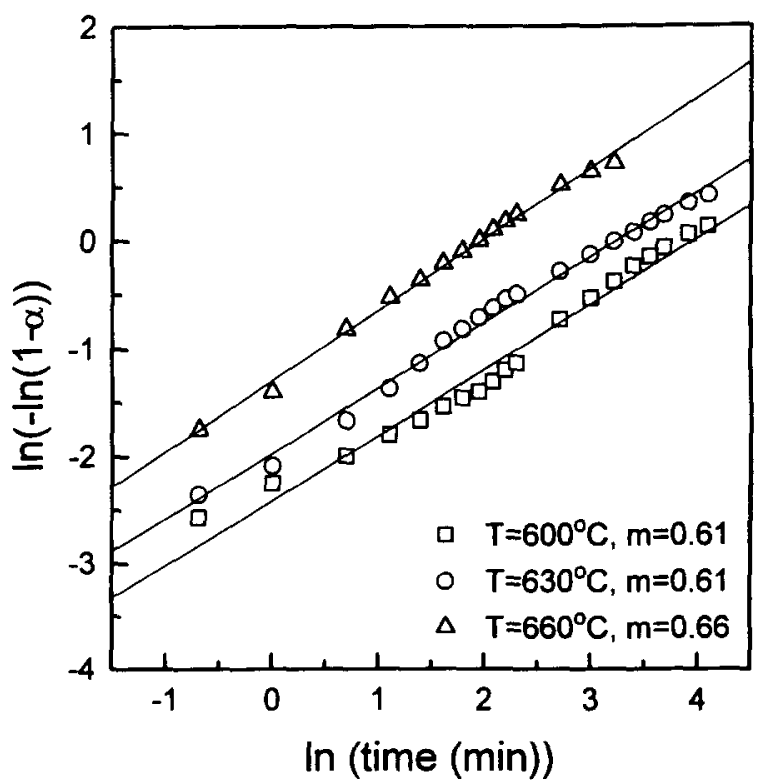

Fig. 6. Plot of $\ln (-\ln (1-\alpha))$ vs $\ln t$ for the formation process of $\mathrm{SrBi}_{2} \mathrm{Ta}_{2} \mathrm{O}_{9}$. 
Table 1. Reaction rate constant $(k)$ and the linearity coefficient (R) of the function of conversion with reaction time based on the Ginstling-Brounshtein and Jander's modeis

\begin{tabular}{lcccc}
$\begin{array}{l}\text { Heating } \\
\text { temperature } \\
\left({ }^{\circ} \mathrm{C}\right)\end{array}$ & \multicolumn{2}{c}{ Ginstling-Brounshtein model } & \multicolumn{2}{c}{ Jander's model } \\
600 & $\mathrm{k}\left(\min ^{-1}\right)$ & $\mathrm{R}$ & $\mathrm{k}\left(\min ^{1}\right)$ & $\mathrm{R}$ \\
630 & 0.0014 & 0.996 & 0.0018 & 0.996 \\
660 & 0.0025 & 0.995 & 0.0032 & 0.998 \\
& 0.0081 & 0.991 & 0.0012 & 0.997
\end{tabular}

$$
\mathrm{k}=\mathrm{k}_{\mathrm{o}} \exp (-\mathrm{E} / \mathrm{RT})
$$

the activation energy (E) of the reaction can be derived. Figure 7 illustrates the plot of $\log (\mathrm{k})$ vs $1 / \mathrm{T}$ for both models. From the slope of the line in Fig. 7, the activation energy for $\mathrm{SrBi}_{2} \mathrm{Ta}_{2} \mathrm{O}_{9}$ formation was calculated to be $210.7 \mathrm{~kJ} \mathrm{~mol}^{-1}$ for Jander's model, and $194.3 \mathrm{~kJ} \mathrm{~mol}^{-1}$ for GinstlingBrounshtein model. Taking possible experimental errors into consideration, these two derived activation energies are accurately quite close.

\subsection{Decomposition of $\mathrm{SrBi}_{2} \mathrm{Ta}_{2} \mathrm{O}_{9}$}

For examining the thermal stability of $\mathrm{SrBi}_{2} \mathrm{Ta}_{2} \mathrm{O}_{9}$, the pressed $\mathrm{SrBi}_{2} \mathrm{Ta}_{2} \mathrm{O}_{9}$ pellets were heated at elevated temperatures. The XRD patterns of the ground powder of the heated pellets are shown in Fig. 8. After $1100^{\circ} \mathrm{C}$ heating, only $\mathrm{SrBi}_{2} \mathrm{Ta}_{2} \mathrm{O}_{9}$ was identified; however, when the temperature was raised to $1250^{\circ} \mathrm{C}, \mathrm{SrTa}_{2} \mathrm{O}_{6}$ was found to coexist with $\mathrm{SrBi}_{2} \mathrm{Ta}_{2} \mathrm{O}_{9}$. The appearance of $\mathrm{SrTa}_{2} \mathrm{O}_{6}$ was caused by the thermal decomposition of $\mathrm{SrBi}_{2}$. $\mathrm{Ta}_{2} \mathrm{O}_{9}$. After $1300^{\circ} \mathrm{C}$ heating, the amount of

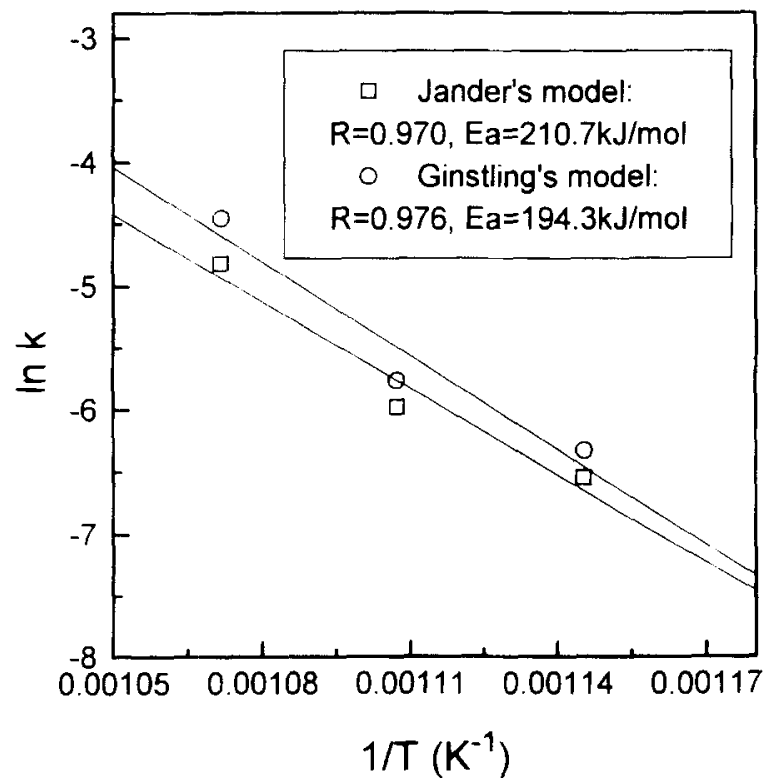

Fig. 7. Plot of $\ln (\mathrm{k})$ vs $1 / \mathrm{T}$ for the formation process of $\mathrm{SrBi}_{2} \mathrm{Ta}_{2} \mathrm{O}_{9}$.

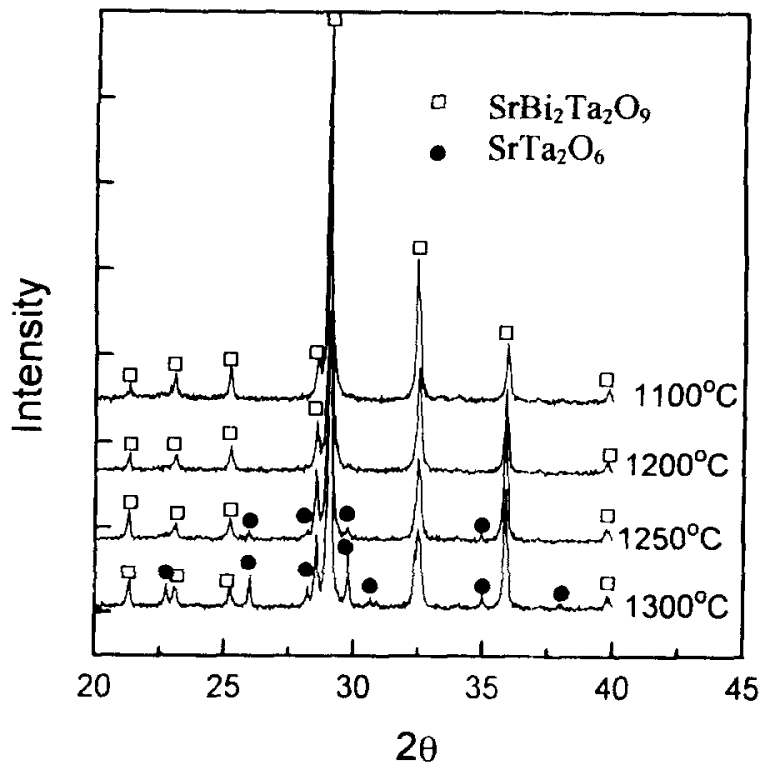

Fig. 8. X-ray diffraction patterns of the ground powder of $\mathrm{SrBi}_{2} \mathrm{Ta}_{2} \mathrm{O}_{9}$ pellets heated at $1100,1200,1250$. and $1300^{\circ} \mathrm{C}$ respectively

$\mathrm{SrTa}_{2} \mathrm{O}_{6}$ further increased with a corresponding reduction in that of $\mathrm{SrBi}_{2} \mathrm{Ta}_{2} \mathrm{O}_{9}$. The surface of these heated specimens was also examined via $X R D$. Figure 9 compares the relative amount of $\mathrm{SrTa}_{2} \mathrm{O}_{6}$ between the bulk and the surface of the heated specimens. The relative amount of $\mathrm{SrTa}_{2} \mathrm{O}_{6}$ was calculated by dividing the diffraction intensity of the major peak of $\mathrm{SrTa}_{2} \mathrm{O}_{6}$ at $2 \theta=29.6^{\circ}$ by the sum of the intensity of the major peak of $\mathrm{SrBi}_{2}$. $\mathrm{Ta}_{2} \mathrm{O}_{9}$ at $2 \theta=28.4^{\circ}$ and that of $\mathrm{SrTa}_{2} \mathrm{O}_{6}$ at $2 \theta=29.6^{\circ} . \mathrm{SrTa}_{2} \mathrm{O}_{6}$ was also found to start forming on surface from above $1200^{\circ} \mathrm{C}$ : moreover, the amount of $\mathrm{SrTa}_{2} \mathrm{O}_{6}$ on surface was significantly greater than that in bulk. After $1300^{\circ} \mathrm{C}$ heating.

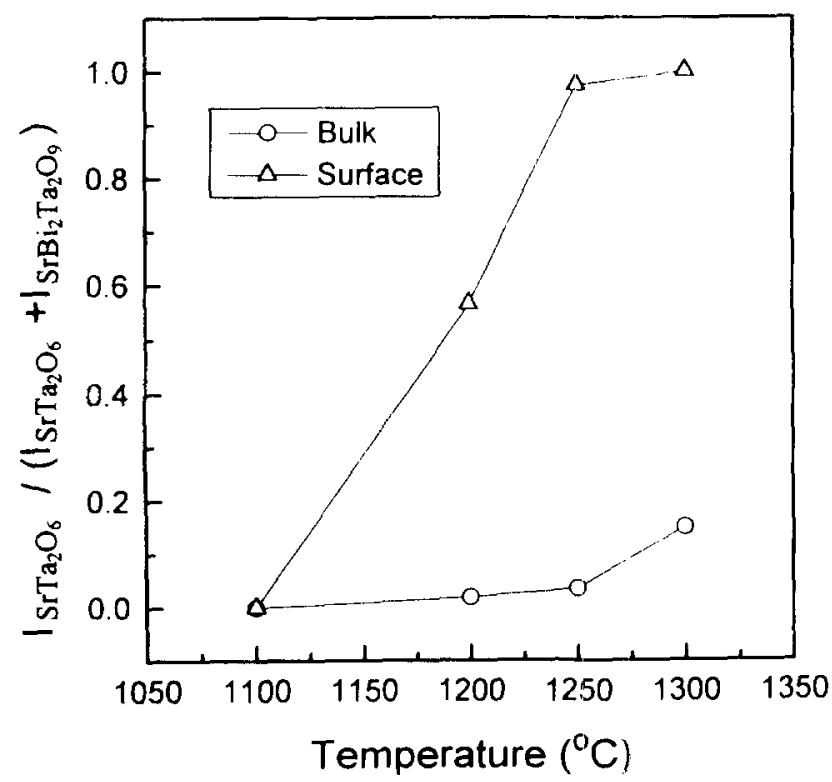

Fig. 9. Relative amounts of $\mathrm{SrTa}_{2} \mathrm{O}_{6}$ present in the bulk and on the surface of $\mathrm{SrBi}_{2} \mathrm{Ta}_{2} \mathrm{O}_{9}$ pellets at various heating temperatures. 


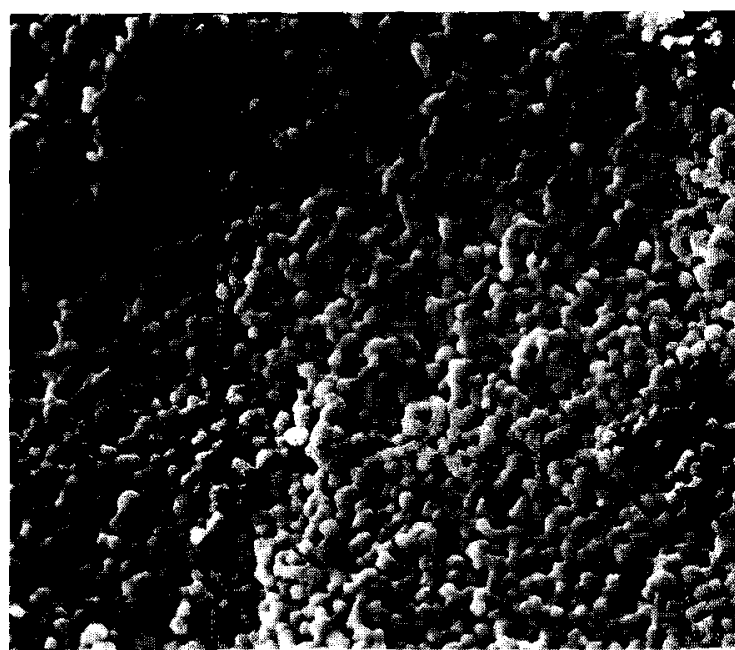

(a)

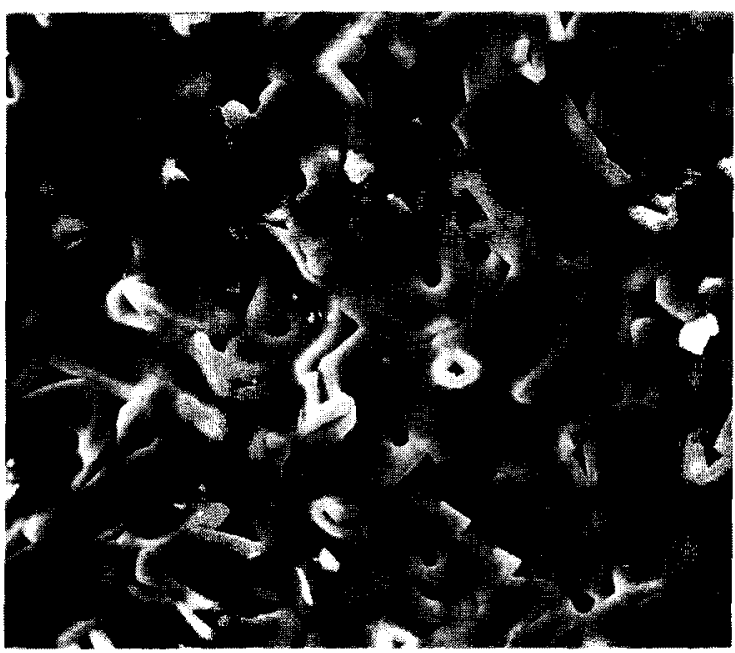

(b)

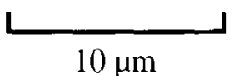

Fig. 10. Scanning electron micrographs of the $\mathrm{SrBi}_{2} \mathrm{Ta}_{2} \mathrm{O}_{9}$ pellets heated at (a) $1100^{\circ} \mathrm{C}$ and (b) $1250^{\circ} \mathrm{C}$.

only $\mathrm{SrTa}_{2} \mathrm{O}_{6}$ was found on the specimen surface. On the other hand, merely $15 \% \quad \mathrm{SrTa}_{2} \mathrm{O}_{6}$ was formed in bulk.

The surface microstructures of the specimens heated at 1100 and $1250^{\circ} \mathrm{C}$ are shown Fig. 10. At $1100^{\circ} \mathrm{C}$ (before decomposition), the microstructure appeared to be uniform, and $\mathrm{SrBi}_{2} \mathrm{Ta}_{2} \mathrm{O}_{9}$ grains with a size of around $0.6 \mu \mathrm{m}$ were observed. When $\mathrm{SrBi}_{2} \mathrm{Ta}_{2} \mathrm{O}_{9}$ became decomposed, the microstructure drastically varied. Observing in the $1250^{\circ} \mathrm{C}$ heated specimen as shown in Fig. $10(\mathrm{~b})$, the grain size rapidly increased to $2-8 \mu \mathrm{m}$, and the shape of these grains became rather irregular. From the EDS analysis, the composition of these grains was found to primarily consist of strontium and tantalum with a ratio of around $1: 2$; therefore, these grains were confirmed to be $\mathrm{SrTa}_{2} \mathrm{O}_{6}$.

According to the above results, the decomposition reaction of $\mathrm{SrBi}_{2} \mathrm{Ta}_{2} \mathrm{O}_{9}$ can be expressed via a balanced stoichiometric equation as below:

$$
\mathrm{SrBi}_{2} \mathrm{Ta}_{2} \mathrm{O}_{9} \rightarrow \mathrm{SrTa}_{2} \mathrm{O}_{6}+\mathrm{Bi}_{2} \mathrm{O}_{3}
$$

Since the amount of $\mathrm{SrTa}_{2} \mathrm{O}_{6}$ on surface is greater than that in bulk, it is reasonable to suggest that the decomposition process of $\mathrm{SrBi}_{2} \mathrm{Ta}_{2} \mathrm{O}_{9}$ begins from the surface of specimens. At the temperatures where the decomposition of $\mathrm{SrBi}_{2} \mathrm{Ta}_{2} \mathrm{O}_{9}$ occurs, the vapour pressure of $\mathrm{Bi}_{2} \mathrm{O}_{3}$ is quite high. As $\mathrm{SrBi}_{2}$ $\mathrm{Ta}_{2} \mathrm{O}_{9}$ gets decomposed, $\mathrm{Bi}_{2} \mathrm{O}_{3}$ will evaporate out gradually. On the specimen surface $\mathrm{Bi}_{2} \mathrm{O}_{3}$ is able to easily to evaporate out from specimens; therefore, the decomposition process starts from specimen surface. Based on the above results, in attempt to prevent the decomposition of $\mathrm{SrBi}_{2} \mathrm{Ta}_{2} \mathrm{O}_{9}$, reducing the heating temperatures to be below $1200^{\circ} \mathrm{C}$ and increasing the atmosphere of bismuth in the heating environment are considered to be practicable strategies.

\section{CONCLUSIONS}

Ferroelectric layered-perovskite $\mathrm{SrBi}_{2} \mathrm{Ta}_{2} \mathrm{O}_{9}$ was successfully prepared through a new process using $\mathrm{BiTaO}_{4}$ as the precursor. Heating the mixtures of $\mathrm{BiTaO}_{4}$ and $\mathrm{SrCO}_{3}$ at $800^{\circ} \mathrm{C}$ resulted in the formation of a single phase of $\mathrm{SrBi}_{2} \mathrm{Ta}_{2} \mathrm{O}_{9}$. During the reaction process, no intermediate phase was observed, revealing that the formation process was a direct reaction between two constituent compounds. Through the isothermal analysis of the reaction kinetics, the controlling reaction in the formation process of $\mathrm{SrBi}_{2} \mathrm{Ta}_{2} \mathrm{O}_{9}$ was determined to be the diffusion process. The diffusion-controlled models using Ginstling-Brounshtein and Jander theories were found to well fit the experimental results. Based on Ginstling-Brounshtein and Jander models, the activation energy of the diffusion process was calculated to be $194.3 \mathrm{~kJ} \mathrm{~mol}^{-1}$ and $210.7 \mathrm{~kJ} \mathrm{~mol}^{-1}$, respectively. The crystalline structure of $\mathrm{SrBi}_{2} \mathrm{Ta}_{2} \mathrm{O}_{9}$ was found to remain stable at temperatures up to $1100^{\circ} \mathrm{C}$. However, this compound became unstable from $1200{ }^{\circ} \mathrm{C}$, and dissociated into $\mathrm{SrTa}_{2} \mathrm{O}_{6}$ and $\mathrm{Bi}_{2} \mathrm{O}_{3}$. The decomposition process started from the surface of specimens and subsequently progressed towards the interior.

\section{REFERENCES}

1. SCOTT, J. F., PAZ, DE ARAUJO C. A., Ferroelectric memories. Science, 246 (1989) 1400-1405.

2. SPIERINGS, G. A. C. ULENAERS, M. J. E., KAMPSCHOER, G. L. M., VAN, HAL H. A. M. \& LARSEN, P. K., Preparation and ferroelectric properties of 
$\mathrm{PbZr}_{0.53} \mathrm{Ti}_{0.47} \mathrm{O}_{3}$ thin film by spin coating and metaorganic decompositon. J. Appl. Phys. 70 (1991) 2290.

3. PAZ, DE ARAUJO C. A., CUCHIARO, J. D., SCOTT, M. C. \& MCMILLAN, L. D., Layered superlattice material applications background of the invention. Inter. Patent Appl. WO93/12542, 1993.

4. SCOTT, J. F., ROSS, F. M., PAZ, DE ARAUJO C. A. SCOTT, M. C. \& HUFFMAN, M., Structure and device characteristics of $\mathrm{SrBi}_{2} \mathrm{Ta}_{2} \mathrm{O}_{9}$-based nonvolatile random-access memories. Mater. Res. Soc. Bull. 21 (1996) 3339.

5. AURIVILLUS, B., Mixed bismuth oxides with layer lattices, I. The structure type of $\mathrm{CaNb}_{2} \mathrm{Bi}_{2} \mathrm{O}_{9}$. Arkir für kemi, 54 (1949) 463-80

6. SMOLENSKII, G. A., ISUPOV, V. A. \& AGRANOVSKAYA, A. I., Ferroclectrics of oxygen-octahedral type with a layer structure. Fiz. Tverdogo Tela., 3 (1961) 895-901.

7. SUBBARAO, E. C., A family of ferroelectric bismuth compounds. J. Phys. Chem. Solids, 23 (1962) 665-676.

8. DESU, S. B. \& VIJAY, D. P.. Novel fatigue-free layered structure ferroelectric thin films. Mater. Sci. Eng., B32 (1995) 75-81

9. DAT, R. D., LEE, J. K., AUCIELLO, O. \& KINGON, A. I.. Pulsed laser ablation synthesis and characterization of layered $\mathrm{Pt} / \mathrm{SrBi}_{2} \mathrm{Ta}_{2} \mathrm{O}_{9} / \mathrm{Pt}$ ferroelectric capacitors with practically no polarization fatigue. Appl. Phys. Lett. 67 (1995) 572574
10. LI. T., ZHU, Y., DESU. S. B., PENG. C. H. \& NAGATA, M., Metalorganic chemical vapor deposition of ferroelectric $\mathrm{SrBi}_{2} \mathrm{Ta}_{2} \mathrm{O}_{9}$ thin films. Appl. Phis. Lett. 68 (1996) 616-618.

11. CHU, P. Y., JONES, R. E.. ZURCHER, Jr, P., TAY LOR, D. J., JIANG, B. P. D. \& GILLESPIE, S. J. Characteristics of spin-on ferroelectric $\mathrm{SrBi}_{2} \mathrm{Ta}_{2} \mathrm{O}_{9}$ thin film capacitors for FERAM applications. I. Marer. Res. 11 (1996) 1065-1068.

12. AMANUMA, K., HASE, T. \& MIYASAKA, Y.. Preparation and ferroelectric properties of $\mathrm{SrBi}_{2} \mathrm{Ta}_{2} \mathrm{O}_{4}$ thin films. Appl. Phys. Lett., 66 (1995) 221223

13. LU. C. H.\& FANG, B. K., Synthesis process and sintering behavior of layered-perovskite barium bismuth tantalate ceramics. J. Mater. Res., (in press)

14. HANCOCK, J. D. \& SHARP. J. H. Method of comparing solid-statc kinctics data and its application to the decomposition of kaolinite, brucite, and $\mathrm{BaCO}_{3} . J . \mathrm{Am}$. Ceram. Soc.. 55 (1972) 74-77.

15. AVRAMI, M., Kinetics of phase change: I. $J$ Chem Phys., 7 (1939) 1103-1112.

16. EROFE'EV, B. V.. Generalized equation of chemical kinetics and its application in reactions :nvolving solids. Acad Sri VISSR, 52 (1946) $511 \ldots 514$

17. GinStLing, A. M. \& BROUNShTEiN, V. I.. Concerning the diffusion kinetics of reactions in spherical particles. J. Appl. Chem. USSR, 23 (1950) 1327-1338.

18. JANDER W.. Reactions in solid state at high temperatures: I. Z. Anorg. Allgem. Chem., 163 (1927) 1-30. 